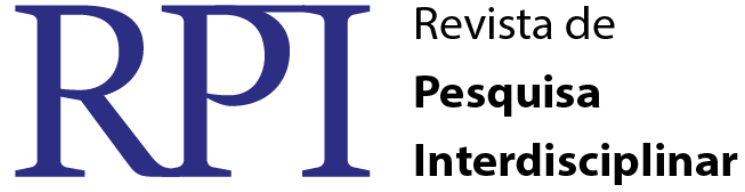

\section{ADESÃO DE DOCENTES ÀS METODOLOGIAS ATIVAS COMO FERRAMENTA DE ENSINO-APRENDIZAGEM NO ENSINO SUPERIOR}

\author{
Rozane Pereira de Sousa ${ }^{1}$ \\ Maria do Carmo Andrade Duarte de Farias ${ }^{1}$ \\ Kennia Sibelly Marques de Abrantes Sucupira ${ }^{1}$ \\ Belijane Marques Feitosa ${ }^{1}$
}

\begin{abstract}
RESUMO
Trata-se de uma revisão integrativa que objetivou analisar a produção científica sobre a adesão às metodologias ativas como ferramenta de ensino-aprendizagem no ensino superior. Os dados foram coletados nas bases de dados Scielo e BDTD, com recorte temporal entre os anos 2008 e 2018, utilizando-se os descritores: "metodologias ativas", "ensino", "docentes". A amostra constituiu em 9 artigos. As publicações sobre a adesão às metodologias ativas como ferramenta de ensino-aprendizagem no ensino superior têm sido tênues, demonstrando que ainda há muito a avançar nesse assunto. Conclui-se que a maior parte dos estudos evidencia efeitos positivos com a aplicação de novas estratégias de ensino e ainda, corrobora a necessidade de mudanças na educação no ensino superior. Também foi possível constatar que as metodologias ativas de ensino representam uma nova forma de fazer e pensar a Educação.
\end{abstract}

Palavras-chave: Metodologias Ativas. Ensino Superior. Docentes.

\section{ACCESSION OF TEACHERS TO ACTIVE METHODOLOGIES AS A TOOL FOR TEACHING-LEARNING IN HIGHER EDUCATION}

\begin{abstract}
It is an integrative review that aimed to analyze the scientific production on the adherence of active methodologies as a teaching-learning tool in higher education. The data were collected in the Scielo and BDTD databases, with a temporal cut between the years 2008 and 2018, using the descriptors: "active methodologies", "teaching", "teachers". The sample consisted of 9 articles. The publications on adherence to active methodologies as a teaching-learning tool in higher education have been tenuous, demonstrating that there is still much to be done in this area. It is concluded that most of the studies show positive effects with the application of new teaching strategies and also, corroborates the need for changes in education in higher education. It was also possible to verify that the active methodologies of education represent a new way of doing and thinking about Education.
\end{abstract}

Keywords: Active Methodologies. Higher Education. Teachers.

\section{INTRODUÇÃO}

\footnotetext{
${ }^{1}$ Universidade Federal de Campina Grande- UFCG.
} 
O cenário da educação vem sofrendo transformações nas últimas décadas; em especial, as concepções e técnicas de ensino têm sido questionadas (PAIVA. et al, 2016).

As práticas pedagógicas tradicionais ainda são utilizadas com frequência. No entanto, como alternativa à prática tradicional surgem as metodologias ativas, que possibilitam ao estudante atuar de maneira ativa na construção de seu conhecimento (PEIXOTO, 2016).

Nas metodologias ativas de aprendizagem, o aprendizado se dá a partir de problemas e situações reais; os mesmos que os alunos vivenciarão depois na vida profissional, de forma antecipada, durante o curso (MORAN, 2016).

Hodiernamente, a qualidade da docência se manifesta na combinação do trabalho em grupo com a personalização, no incentivo à colaboração entre todos e, ao mesmo tempo, que cada um possa personalizar seu percurso (BACICH; TANZI NETO; TREVISANI, 2015).

Entretanto, estudos revelam a resistência de grupos que ainda pensam que o docente tem que "dar o conteúdo e avaliar"; que o conteúdo seja resumido e disponibilizado em slides, para facilitar a aprendizagem. Dessa forma, ainda vivemos uma sociedade motivada por condições que mesmo criticada, não tem como fugir: "a ideia de que a educação não vai mudar" (CAVALI, 2016).

Corroborando, Morán (2016) afirma que muitas escolas e docentes preferem manter os modelos de aulas prontas, com roteiros definidos previamente. Esses modelos precisam evoluir para incorporar propostas mais centradas no aluno, na colaboração e personalização.

Partindo desse pressuposto, o docente além de dominar a técnica pedagógica e as competências para desenvolvimento do plano de aula e da avaliação, também deve se perceber como parte de um processo, no qual a forma de se relacionar com o estudante interfere no processo de aprendizagem, considerando ainda que cada indivíduo aprende de forma diferente. Em vista disso, pode-se utilizar: aprendizagem baseada em problemas (PBL), aprendizagem baseada em projetos (PBL), estudo de caso, viagem, entre outras ferramentas que favoreçam o aprendizado.

Considerando o exposto e refletindo sobre as mudanças de paradigma no Ensino Superior surgiu à pergunta norteadora desse estudo: Qual a adesão dos docentes ás metodologias ativas como ferramenta de ensino-aprendizagem no ensino superior? Assim, este estudo teve como objetivo analisar a produção científica sobre a adesão as metodologias ativas como ferramenta de ensino-aprendizagem no ensino superior. 
O estudo apresenta relevância social, pois, por meio do levantamento das evidências científicas existentes acerca da adesão às metodologias ativas como ferramenta de ensinoaprendizagem pode-se proporcionar uma contribuição prática para melhorar o nível de adesão dos docentes às metodologias ativas de ensino aprendizagem. Fornecer uma visão mais ampla sobre o papel das metodologias ativas e sua relevância no ensino superior, abordando questões referentes ao ato de ensinar, tornando-o mais consciente e proveitoso. O estudo contribuirá ainda para a formação de alunos pro ativos, ao constituir um material de consulta que poderá ser utilizado para esclarecer dúvidas dos docentes acerca da temática explorada.

\section{METODOLOGIA}

Trata-se de uma revisão integrativa da literatura que compromete-se com o seguimento de critérios bem definidos sobre a coleta de dados, análise e apresentação dos resultados. Dessa forma, foram adotadas as seguintes etapas indicadas para a constituição da revisão integrativa da literatura: 1) seleção da pergunta de pesquisa; 2) definição dos critérios de inclusão de estudos e seleção da amostra; 3) representação dos estudos selecionados em formato de tabela; 4) análise crítica dos achados, identificando diferenças e conflitos; 5) interpretação dos resultados e 6) reportar, de forma clara, a evidência encontrada (MENDES; SILVEIRA; GALVÃO, 2008).

Para o levantamento bibliográfico, buscou-se artigos científicos na literatura brasileira publicados, no recorte temporal 2008 a 2018, nas seguintes bases de dados: Scientific Electronic Library Online (Scielo) e Biblioteca digital de teses e dissertações (BDTD). Foram utilizados os descritores: "metodologias ativas", “ensino", "docentes". Estes descritores foram associados utilizando os operadores boleanos AND e OR.

Foram identificados 124 estudos nas bases de dados abordadas, sendo 106 da Scielo e 18 da Biblioteca digital de teses e dissertações -BDTD. Os critérios de elegibilidade para inclusão na amostra contemplavam estudos que abordassem o tema proposto; tivessem sido publicados no recorte temporal supracitado e nos idiomas português ou inglês. A partir dos resultados da busca, foi executado o trabalho de eliminação de artigos não correlatos à temática em estudo, artigos não disponíveis de forma gratuita na íntegra e duplicidades. Após uma análise minuciosa, nove (9) se adequavam aos critérios de inclusão, compondo a amostra final desta revisão integrativa (Figura 1). 
Figura 1 - Operacionalização do processo de seleção (etapas 03 e 04). Cajazeiras, PB, Brasil, 2019.

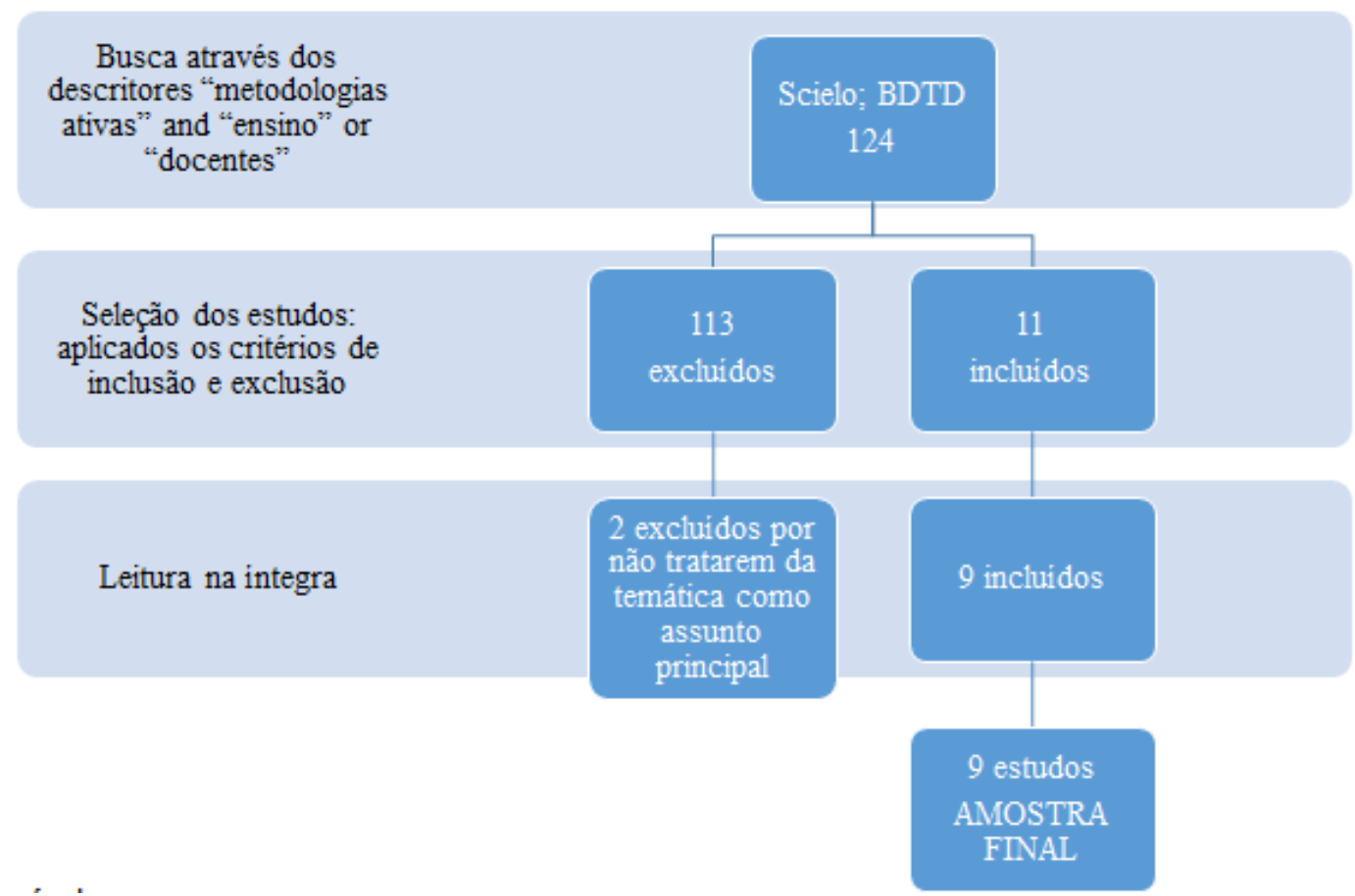

Fonte: Élaboração própria.

\section{RESULTADOS E DISCUSSÃO}

Após a leitura minuciosa dos artigos, os estudos incluídos na revisão foram analisados de forma sistemática em relação aos seus títulos, autores, ano de publicação, objetivos, métodos e resultados, permitindo que o leitor analise o conhecimento pré-existente sobre o tema investigado (Quadro 1).

Quadro 1- Caracterização dos estudos incluídos na revisão integrativa. Cajazeiras-PB, 2019

Título Ano Autor(es) Objetivos Resultados

Integralidade na formação do ensino superior: metodologias ativas de aprendizagem 2018 Lacerda e Santos Discutir a integralidade na formação do ensino superior no Brasil, no que tange as demandas/exigências sociais e mercadológicas do século XXI, na perspectiva de promover uma reflexão dos modelos e métodos de ensino e aprendizagem não tradicionais. O professor deve entender que a formação continuada é o único caminho da docência, abrindo portas, inclusive, para o conhecimento de novas metodologias de 
aprendizagem, mais estimulantes, que apresentam melhores resultados.(...) As estratégias utilizadas pelos professores devem ser convidativas, para que o aluno participe ativamente e, ao mesmo tempo, para que o sujeito se sinta confortável em expor suas ideias.

Aprendizagem Cooperativa e a Formação do Médico Inserido em Metodologias Ativas: um Olhar de Estudantes e Docentes 2018 Conceição e Moraes Explorar a percepção de estudantes e docentes sobre aprendizagem cooperativa em um currículo médico baseado em métodos ativos (Aprendizagem Baseada em Problemas e Problematização). Em relação aos docentes, $85 \%$ se graduaram em método tradicional, tendo de 16 a 30 anos de formação e de 15 a 21 anos de trabalho com métodos ativos, sendo que 92\% deles com pósgraduação. Os resultados quantitativos e qualitativos foram convergentes, estudantes e docentes apresentaram concepções análogas quanto aos benefícios da aprendizagem cooperativa em pequenos grupos, julgando que habilidades de comunicação, raciocínio crítico, interdependência positiva, avanços em trabalho em equipe, além de boa aquisição de conhecimento cognitivo são garantidos nesse processo.

Pressupostos pedagógicos das atuais propostas de formação superior em saúde no Brasil: origens históricas e fundamentos teóricos 2016 Conterno e Lopes Demonstrar que as metodologias inspiradas em pressupostos pedagógicos não diretivos, difundidas pelo Ministério da Saúde como inovadoras no campo da formação em saúde, se contextualizadas historicamente, perdem sua inventividade e originalidade. $O$ professor deve ser facilitador tendo a função de organizar o grupo para que busque as informações, conhecimentos, avaliados como necessários para resolver dado problema.(...) Ao apresentar os fundamentos teóricos dos pressupostos pedagógicos difundidos no campo da formação superior em saúde como inovadores, evidencia-se a significativa influência do pensamento das Pedagogias Ativas, respaldados nos ideais do escolanovismo, movimento que desde o século passado tem influenciado o campo da educação.

Concepções de docentes e discentes acerca de metodologias de ensino-aprendizagem: análise do caso do Curso de Enfermagem da Universidade Estadual Vale do Acaraú em Sobral - Ceará 2009 Teófilo e Dias Conhecer a concepção de docentes e discentes do Curso de Enfermagem da Universidade Estadual Vale do Acaraú acerca de metodologias de ensinoaprendizagem.Em relação às metodologias de ensino-aprendizagem, observou-se que as concepções docentes se encaminham para a crítica, ou seja, buscam incorporar algumas tendências que impulsionam a transformação. As expressões: focada no aluno; aluno crítico; 
visão construtivista, e posição de pensar e de ver a necessidade do conhecimento denotam a busca docente pela "imunização do bancarismo", na qual o educador busca construir uma verdadeira aprendizagem significativa (Freire, 1998, p.19).

Metodologias ativas: estratégias propostas em práticas pedagógicas no curso de publicidade e propaganda: período de 2013 a 20172018 Favaro e Mizukami Identificar quais metodologias de ensino utilizam e se elas são recomendadas pelo Projeto Político Pedagógico. Foi possível verificar que os educadores têm formação docente em diferentes cursos, inclusive em Comunicação Social, desconhecendo as metodologias ativas e se utilizando em sala de aula de estratégias de ensino semelhantes àquelas que aprenderam enquanto alunos ou desenvolveram alguma forma própria de transmitir conhecimentos.

Docência no ensino superior: o uso das mídias digitais como estratégia pedagógica

2011 Lames e Slomski Investigar de que modo docentes de uma IES do estado de São Paulo estão utilizando as mídias digitais em suas aulas. Independentemente da geração que o docente pertence e do contexto tecnológico em que viveu, ele é capaz de aprender e saber lidar com o novo, basta que esteja aberto à aprendizagem e encontre na IES fomento às suas experiências e a oportunidade de desenvolver suas competências para o uso das novas tecnologias.

O desenvolvimento da competência crítica e reflexiva no contexto de um currículo integrado 2013 Alves e Oliveira Analisar a formação crítica e reflexiva no contexto de um currículo integrado. As categorias empíricas em relação à prática docente foram: levar estudante a relacionar os conteúdos teóricos à prática; fazer perguntas, aplicar metodologias ativas e usar processos avaliativos. Quanto às fortalezas foram mencionadas: a integração de conteúdos básico-clínico, a manutenção das áreas de conhecimento e as metodologias ativas. As fragilidades foram: o tempo restrito, o contexto do processo de trabalho docente, o despreparo e a falta de intencionalidade do professor e a postura do estudante frente à nova situação de aprendizado.

Percepções sobre o uso das mídias digitais como recurso pedagógico de docentes que atuam em cursos de Ciências Contábeis 2015 Camargo e Slomski Conhecer e analisar as percepções sobre o uso das mídias digitais como recurso pedagógico de docentes que atuam em cursos de Ciências Contábeis oferecidos na modalidade a distância por duas instituições de Ensino Superior - IES - brasileiras, procurando identificar avanços e dificuldades que podem impactar o desempenho docente diante dos desafios e exigências quanto ao uso das tecnologias na educação superior. $\quad$ Os docentes possuem um bom 
nível de conhecimento do uso das mídias digitais interativas, pois 95\% dos docentes afirmam se utilizar de ambientes virtuais em suas aulas.

Situações-problema Simuladas: uma Análise do Processo de Construção 2011

Aquilante et al. Identificar e avaliar a construção das situações-problema (SP) utilizadas na Atividade Curricular Situações-Problema do curso de Medicina da Universidade de 2006 a 2009. O professor deve elaborar a situação-problema considerando as condições de aplicabilidade, o material didático, os recursos humanos, as fontes de informação, o tempo, a avaliação e os objetivos propostos. Caso não tenha conhecimento acerca do assunto que será abordado, é interessante que se familiarize por meio de estudo e entrevista com especialistas. Para poder planejar adequadamente a atividade, também precisa conhecer a realidade, investigando as necessidades dos estudantes.

Fonte: Elaboração própria

Em relação à titulação, a maioria dos autores é doutor 9 (42\%), $2(9 \%)$ são mestres e $10(48 \%)$ dos autores não informaram a titulação. Quanto à profissão, 13 (62\%) são docentes, 5 (24\%) são médicos, 2 (9\%) são enfermeiros e 1 (4,5\%) é secretário de educação.

Os estudos foram desenvolvidos nas regiões Sudeste $7(77,77 \%)$ e Nordeste 2 $(22,22 \%)$, com destaque para a cidade de São Paulo (67\%).

Ao analisarmos os delineamentos de pesquisa mais frequentes na amostra estudada, identificamos que $4(44,44 \%)$ utilizaram a abordagem metodológica descritiva qualitativa, 2 $(20,22 \%)$ desenvolveram estudos de cunho reflexivo, $2(20,22 \%)$ foram estudos de caso e 1 $(11,11 \%)$ estudo utilizou abordagem quantiqualitativa.

A aprendizagem significativa, o professor facilitador, o aprender a aprender, a metodologia ativa de aprendizagem e a aprendizagem por problemas são demonstradas no estudo de Conterno e Lopes (2016) como a base para os pressupostos pedagógicos das metodologias ativas, as quais passaram a ser apontadas como representantes do que seria mais avançado, moderno e politicamente responsável no campo da formação dos sujeitos.

Borges e Alencar (2014) defendem uma visão de que para ser um bom professor universitário não basta ter um vasto conhecimento na área da disciplina lecionada associada a uma boa oratória, pois os estudantes do nível superior na atualidade chegam com suas personalidades formadas, possuidores de uma bagagem de conhecimento grande decorrentes de uma sociedade globalizada. 
Outro aspecto fundamental no que se refere à adesão as metodologias ativas como ferramenta de ensino-aprendizagem no ensino superior pode ser percebido na abordagem do estudo de Teófilo e Dias (2009), para esses estudiosos, a complexidade de um processo de mudança de concepções é imensa e exigem, dos sujeitos interessados, paciência e perseverança, pois são as pessoas que devem ter suas práticas resignificadas.

Tais considerações apontam a necessidade de compreender que as mudanças fazem parte do processo de construção do próprio sujeito, o cenário educacional é múltiplo, porém não se podem desconsiderar as peculiaridades de cada sujeito, e o que isso implica nesse processo de mudança e concretização de uma nova "cultura acadêmica".

Ainda sobre esse propósito, Favaro e Mizukami (2018) destacam que os docentes não estão familiarizados com metodologias de ensino ativas, além das tradicionais, dessa forma não estimulam os alunos para que "ouçam, vejam e pratiquem" aquilo que devem saber e fazer, se tornando dessa forma os protagonistas em sala de aula, contrapondo ao esperado que é o protagonismo estudantil.

Cabe aqui a reflexão quanto à formação dos docentes universitários, pois, questiona-se se esses profissionais, independente da área de formação, foram preparados para atuarem na academia frente ao contexto das novas tecnologias educacionais.

Morán (2015) contribui com a discussão ao alertar que os métodos tradicionais faziam sentido quando o acesso à informação era difícil, mas com o advento da internet e a divulgação aberta de muitos cursos e materiais, a postura do professor deve ser adaptada a essa realidade.

As limitações podem ser superadas, na percepção dos próprios docentes, mediante processos formativos em que as tecnologias sejam entendidas para além do uso instrumental, mas como potencializadoras da expressão e produção cultural (CAMARGO e SLOMSKI, 2015).

No trabalho de Lacerda e Santos (2018) percebeu-se que os educadores têm papel fundamental na atualização constante dos conteúdos, cerne da rotina universitária, devendo estar atentos à evolução das ciências e reforçando a importância da pesquisa para o processo de aprendizagem continuada.

Corroborando participantes do estudo de Conceição e Moraes (2018) confirmam a necessidade de continuar a investir na sua capacitação, pois existe também a renovação do quadro de professores. Nessa perspectiva, destacamos que a formação continuada do docente 
permite a atualização e a lapidação de suas práticas e posturas, além da compreensão do processo ensino/aprendizagem no qual está inserido.

A formação continuada pode contribuir também na determinação dos objetivos pedagógicos do plano de aula dos docentes, possibilitando levar em conta não somente o domínio cognitivo, os saberes, mas também o desenvolvimento das capacidades de autonomia, negociação, comunicação e responsabilidade diante de situações concretas. (Aquilante et al., 2011).

Os projetos de formação continuada podem constituir espaços para que os docentes possam se apropriar das novas tecnologias de ensino como também possam compartilhar dúvidas, dificuldades e experiências exitosas na adesão às metodologias ativas.

Estudo realizado por Gilboy, Heinerichs e Pazzaglia (2015) reforçam que tanto os professores quanto os alunos tiveram maior satisfação e os alunos melhores resultados de aprendizagem no processo de ensino com o uso de metodologias ativas.

Para avançar nesse entendimento, é necessário relembrarmos os pressupostos de Paulo Freire (1996) acerca da Pedagogia Problematizadora, que enfatiza a resolução de problemas e a construção do conhecimento novo a partir de conhecimentos e experiências prévias dos indivíduos e parte da premissa de que educador e educando aprendem juntos numa relação dinâmica.

Nessa perspectiva, a aplicação de metodologias ativas requer antes de tudo uma nova postura por parte do corpo docente/discente, e, por conseguinte uma nova leitura do processo ensino/aprendizagem, capaz de estabelecer um diálogo profícuo nesse cenário, onde cada sujeito compreenda seu papel na construção e elaboração dos saberes.

Essa tônica discursiva conota que a adesão às metodologias ativas como ferramenta de ensino-aprendizagem no ensino superior tem ganhado um espaço notável, mesmo diante das limitações ou da carência de formações continuadas ainda presentes na atual conjuntura acadêmica, não se pode desestimular o enfrentamento das contradições desse processo na solidificação dessa nova cultura pedagógica capaz de pensar os sujeitos como protagonistas do saber e da história, e não mais meros receptores ou reprodutores de conhecimento carente de reflexão.

Portanto, as evidências científicas demonstram que embora haja uma concepção conservadora do papel do professor, há um segmento dos docentes que evocam a importância da formação pedagógica para a adesão as metodologias ativas, demonstrando uma possibilidade de avanço dos processos educacionais. 


\section{CONSIDERAÇÕES FINAIS}

A maior parte dos estudos evidencia efeitos positivos com a aplicação de novas estratégias de ensino e ainda, corrobora a necessidade de mudanças na educação no ensino superior. Também foi possível constatar que a adesão às metodologias ativas de ensino representam uma nova forma de fazer e pensar a Educação.

As dificuldades enfrentadas pelos docentes apontam para a necessidade de um esforço nacional para a atualização profissional, bem como para a necessidade de um maior investimento em pesquisas que incidam sobre a temática, a partir do reconhecimento de sua importância e da lacuna científica existente.

Dessa forma, espera se que este estudo colabore com as discussões relativas às metodologias ativas no ensino superior no Brasil, a partir de sua contribuição para a elucidação desse cenário nos últimos dez anos, cooperando para a formação de um corpo docente que valorize a formação de sujeitos critico-reflexivos.

\section{REFERÊNCIAS}

ALVES, E. ; OLIVEIRA, M.A.C. O desenvolvimento da competência crítica e reflexiva no contexto de um currículo integrado. 2013. 148 f. Tese (Doutorado em Enfermagem)Universidade de São Paulo, São Paulo, 2013.Disponível em: < http://www.teses.usp.br/teses/disponiveis/83/83131/tde-05062014-115305/> acesso em 26 de janeiro de 2019.

AQUILANTE, A.G. et al. Situações-problema Simuladas: uma Análise do Processo de Construção. Rev. bras. educ. med. Rio de Janeiro, v.35, n.2, 2011. Disponível em: < $\mathrm{http}: / /$ www.scielo.br/scielo.php?script=sci_arttext\&pid=S0100-

$55022011000200002 \&$ lang=pt $>$ acesso em 28 de janeiro de 2019.

BACICH, L.; TANZI NETO, A.; TREVISANI, F. M. (Org.). Ensino híbrido: personalização e tecnologia na educação. Porto Alegre: Penso, 2015.

BORGES, T. S; ALENCAR, G. Metodologias ativas na promoção da formação crítica do estudante: o uso das metodologias ativas como recurso didático na formação crítica do estudante de ensino superior. Cairu em Revista. Salvador, v.3, n.4, 2014. Disponível em: < https://www.ea2.unicamp.br/mdocs-posts/metodologias-ativas-na-promocao-da-formacaocritica-do-estudante-o-uso-das-metodologias-ativas-como-recurso-didatico-na-formacaocritica-do-estudante-do-ensino-superior/> acesso em 28 de janeiro de 2019. 
CAMARGO, A. S. S.; SLOMSKI, V. G. Percepções sobre o uso das mídias digitais como recurso pedagógico de docentes que atuam em cursos de Ciências Contábeis. 2015. 157 f. Dissertação (Mestrado em Ciências Contábeis)-Fundação Escola de Comércio Álvares Penteado - FECAP, São Paulo, 2015. Disponível em: < http://bdtd.ibict.br/vufind/Record/FAAP_a2169cfdbb0153182f8ca603f84d3e87> acesso em 28 de janeiro de 2019

CAVALI, R.C. Metodologias ativas no ensino superior - Uma experiência com projetos integradores. 2016. Disponível em:

$<$ http://educere.bruc.com.br/arquivo/pdf2017/26661_13551.pdf $>$ acesso em 08 de janeiro de 2019

CONCEICAO, C. V. da; MORAES, M. A. A. de. Aprendizagem Cooperativa e a Formação do Médico Inserido em Metodologias Ativas: um Olhar de Estudantes e Docentes. Rev. bras. educ. med. Brasília, v.42, n.4, 2018. Disponível em: < http://dx.doi.org/10.1590/198152712015v42n4rb20180013.> acesso em 28 de janeiro de 2019

CONTERNO, S. de F. R.; LOPES, R. E. Pressupostos pedagógicos das atuais propostas de formação superior em saúde no Brasil: origens históricas e fundamentos teóricos. Revista de avaliação do ensino superior. Sorocaba, v. 21, n. 3, p. 993-1016, nov. 2016 Disponível em: < http://www.scielo.br/pdf/aval/v21n3/1982-5765-aval-21-03-00993.pdf> acesso em 27 de janeiro de 2019

FAVARO, J. E.; MIZUKAMI, M. da G. N. Metodologias ativas: estratégias propostas em práticas pedagógicas no curso de publicidade e propaganda: período de 2013 a 2017. 2018. 136 f. Tese (Educação, Arte e História da Cultura) - Universidade Presbiteriana Mackenzie, São Paulo. Disponível em: < http://tede.mackenzie.br/jspui/handle/tede/3651> acesso em 27 de janeiro de 2019

FREIRE, P. Pedagogia do oprimido. São Paulo: Paz e Terra, 1996.

GILBOY, M. B.; HEINERICHS, S.; PAZZAGLIA, G. Enhancing Student Engagement Using the Flipped Classroom. Journal of Nutrition Education and Behavior. v. 47, n. 1, p. 109$114,2015$.

LACERDA, F. C. B.; SANTOS, L. M. dos. Integralidade na formação do ensino superior: metodologias ativas de aprendizagem. Revista de avaliação do ensino superior. Campinas, v.23, n.3, pp.611-627, 2018. Disponível em: < http://dx.doi.org/10.1590/s141440772018000300003.> acesso em 28 de janeiro de 2019 
LAMES, L. da C. J.; SLOMSKI, V. G. Docência no ensino superior: o uso das mídias digitais como estratégia pedagógica. 2011. 159 f. Dissertação (Mestrado em Controladoria e Contabilidade) - FECAP - Faculdade Escola de Comércio Álvares Penteado, São Paulo, 2011. Disponível em: <http://132.0.0.61:8080/tede/handle/tede/494> acesso em 27 de janeiro de 2019

MORÁN, J. Mudando a educação com metodologias ativas. In: Coleção Mídias Contemporâneas. Convergências Midiáticas, Educação e Cidadania: aproximações jovens. Vol. II Carlos Alberto de Souza e Ofelia Elisa Torres Morales (orgs.). PG: Foca FotoPROEX/UEPG, 2015. Disponível em: <http://www2.eca.usp.br/moran/wpcontent/uploads/2013/12/mudando_moran.pdf> acesso em 05 de janeiro de 2019

PAIVA, M.R.F. et al. Metodologias ativas de ensino aprendizagem: Revisão integrativa. Sanare. Sobral. v.15, n.2, p.145-153, 2016. Disponível em: $<$ https://sanare.emnuvens.com.br/sanare/article/download/1049/595 > acesso em 03 de janeiro de 2019

PEIXOTO, A.G. O uso de metodologias ativas como ferramenta de potencialização da aprendizagem de diagramas de caso de uso. Periódico científico outras palavras. Brasília, v. 12, n. 2, 2016. Disponível em:

$<$ hrevista.faculdadeprojecao.edu.br/index.php/Projecao5/article/download/718/604 > acesso em 03 de janeiro de 2019

TEOFILO, T. J. S.; DIAS, M. S. de A. Concepções de docentes e discentes acerca de metodologias de ensino-aprendizagem: análise do caso do Curso de Enfermagem da Universidade Estadual Vale do Acaraú em Sobral - Ceará. Interface. Botucatu, v.13, n.30, pp.137-151, 2009. Disponível em: < http://www.scielo.br/scielo.php?pid=S141432832009000300012\&script=sci_abstract\&tlng=pt $>$ acesso em 27 de janeiro de 2019. 